\title{
REHABILITASI MEDIK PADA SKOLIOSIS
}

\author{
Jane Pelealu \\ Leonard S. Angliadi \\ Engeline Angliadi
}

\author{
Bagian Ilmu Kedokteran Fisik dan Rehabilitasi Fakultas Kedokteran \\ Universitas Sam Ratulangi Manado \\ Email: jpelealu3103@gmail.com
}

\begin{abstract}
Scoliosis is one of the spine deformities in which a person's spine is bend laterally associated with or without a rotation of the vertebrae. There are several variations in the etiology, onset, prognosis, and therapy of scoliosis, but the effects of untreated scoliosis are the same, as follows: pain, and disturbances in balance, cardiopulmonal function, emotion, behaviour, and ADLs (activities in daily living). The most common symptoms of scoliosis are abnormal deformity of spine which can cause pain, decrease of quality of life, disability, comestic disturbance, functional limitation, pulmonary problems, probabilty of progression at adulthood, dan pyschological disturbance. In physical examination, midline shift of spinous process, asymmetry of the back, rib hump, asymmetry of the scapula, hip, shoulder and pelvis, as well as leg length discrepancy must be carefully examined. Besides that, a radiological examination showing the Cobb angle is also important to do. The therapy of scoliosis includes observation, rehabilitation therapy namely physical modalities, orthoses/brace, exercise, or invasive therapy such as operation. Additionally, the prognosis of scoliosis depends on sex, curve angle at first recognition, type and rotation of curve, and age of onset.
\end{abstract}

Keywords: scoliosis, spine, rehabilitation, exercise, orthoses

\begin{abstract}
Abstrak: Skoliosis adalah deformitas tulang belakang yang ditandai oleh lengkungan ke lateral dengan atau tanpa rotasi tulang belakang. Etiologi, onset, prognosis, dan terapi skoliosis dapat bervariasi, namun akibat skoliosis yang tidak diterapi sama, yaitu nyeri, yang disertai gangguan dalam keseimbangan, fungsi kardiopulmonal, emosional dan perilaku, serta aktivitas kehidupan sehari-hari (AKS). Gejala yang paling umum dari skoliosis ialah adanya suatu lekukan yang tidak normal dari tulang belakang yang dapat berakibat nyeri, penurunan kualitas hidup dan disabilitas, deformitas yang mengganggu secara kosmetik, hambatan fungsional, masalah paru, kemungkinan terjadinya progresifitas saat dewasa, dan gangguan psikologis. Hal-hal yang harus diperhatikan pada pemeriksaan fisik ialah deviasi prosesus spinosus dari garis tengah, punggung yang tampak miring, rib hump, asimetri dari skapula, pinggul, bagian atas dan bawah trunkus (bahu dan pelvis), serta perbedaan panjang tungkai. Selain itu, pemeriksaan radiologik untuk melihat sudut Cobb juga penting untuk dilakukan. Terapi skoliosis dapat berupa observasi, terapi rehabilitasi yaitu pemberian modalitas, ortosis/brace, latihan, atau terapi invasif seperti operasi. Prognosis skoliosis dipengaruhi oleh jenis kelamin, ukuran kurva saat pertama kali ditemukan, tipe dan rotasi kurvatura dan usia saat onset skoliosis.
\end{abstract}

Kata kunci: skoliosis, tulang belakang, rehabilitasi, latihan, ortosis

Skoliosis adalah deformitas tulang belakang yang ditandai oleh lengkungan ke lateral dengan atau tanpa rotasi tulang belakang. Skoliosis dapat berupa skoliosis fungsional yang dapat diperbaiki sedangkan skoliosis struktural yang cenderung 
menetap. ${ }^{1}$ Sekitar $15-20 \%$ dari kasus skoliosis penyebab awalnya tidak diketahui, ${ }^{2}$ serta $80 \%$ kasus skoliosis struktural mempunyai etiologi idiopatik dan biasanya ditemukan pada anak-anak atau remaja. ${ }^{3}$

Etiologi, onset, prognosis, dan terapi skoliosis dapat bervariasi, namun akibat skoliosis berat yang tidak diterapi akan sama, yaitu nyeri disertai berbagai gangguan dalam keseimbangan, fungsi kardipulmonal, emosional, perilaku, dan aktivitas kehidupan sehari-hari (AKS). ${ }^{4,5}$

Tujuan terapi skoliosis ialah untuk menjaga agar kurvatura yang terjadi tetap terkontrol selama pertumbuhan. Terapi skoliosis dapat berupa observasi; terapi rehabilitasi, yaitu: pemberian modalitas, ortosis/brace, dan latihan; atau terapi invasif seperti operasi. ${ }^{1}$

\section{DEFINISI}

Kata skoliosis berasal dari bahasa Yunani skolios yang berarti bengkok. ${ }^{6}$ Skoliosis adalah kelainan tulang belakang yang berupa lengkungan ke samping/ lateral. Jika dilihat dari belakang, tulang belakang pada skoliosis akan berbentuk seperti huruf "C" atau "S" (Gambar 1). Definisi lain menyatakan bahwa skoliosis adalah sebuah tipe deviasi postural dari tulang belakang dengan penyebab apapun, yang dicirikan oleh adanya kurva lateral pada bidang frontal yang dapat berhubungan atau tidak berhubungan dengan rotasi korpus vertebra pada bidang aksial dan sagital.

\section{ETIOLOGI}

Penyebab dan patogenesis skoliosis belum dapat ditentukan dengan pasti. Kemungkinan penyebab pertama ialah genetik. Banyak studi klinis yang mendukung pola pewarisan dominan autosomal, multifaktorial, atau X-linked. Penyebab kedua ialah postur, yang mempengaruhi terjadinya skoliosis postural kongenital. Penyebab ketiga ialah abnormalitas anatomi vertebra dimana lempeng epifisis pada sisi kurvatura yang cekung menerima

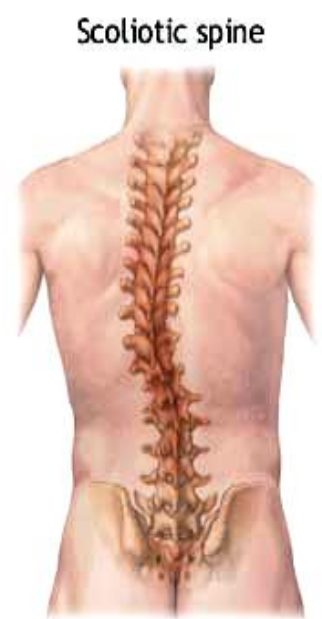

A

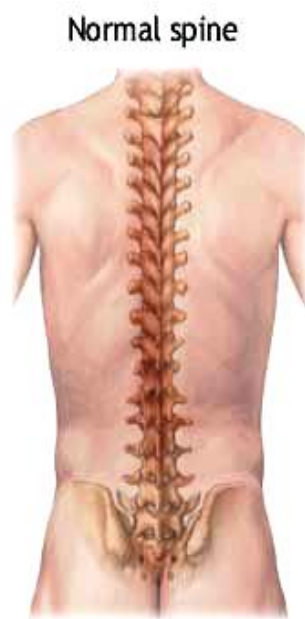

B
Gambar 1. A, Kurvatura spinal pada skoliosis. B, Kurvatura spinal normal. Sumber: Texas Health Resources. ${ }^{8}$

tekanan tinggi yang abnormal sehingga mengurangi pertumbuhan, sementara pada sisi yang cembung menerima tekanan lebih sedikit, yang dapat menyebabkan pertumbuhan yang lebih cepat. Selain itu, arah rotasi vertebra selalu menuju ke sisi cembung kurvatura, sehingga menyebabkan kolumna anterior vertebra secara relatif menjadi terlalu panjang jika dibandingkan dengan elemen-elemen posterior. ${ }^{9}$ Penyebab keempat ialah ketidakseimbangan dari kekuatan dan massa kelompok otot di punggung. ${ }^{10}$ Abnormalitas yang ditemukan ialah peningkatan serat otot tipe I pada sisi cembung dan penurunan jumlah serat otot tipe II pada sisi cekung kurvatura. ${ }^{9,11,12}$ Selain itu, dari pemeriksaan EMG didapatkan peningkatan aktivitas pada otot sisi cembung kurvatura. ${ }^{13}$

\section{KLASIFIKASI}

Skoliosis dibagi atas skoliosis fungsional dan struktural. Skoliosis fungsional disebabkan kerena posisi yang salah atau tarikan otot paraspinal unilateral, yang dapat disebabkan karena nyeri punggung dan spasme otot. $^{3}$ Perbedaan panjang tungkai, herniasi diskus, spondilolistesis, atau penyakit pada sendi panggul juga dapat menyebabkan terjadinya skoliosis 
fungsional. ${ }^{4}$ Pada skoliosis fungsional, tidak terjadi rotasi vertebra yang bermakna, dan biasanya reversibel. ${ }^{3}$ Terapi terhadap penyebab skoliosis dapat memperbaiki kurvatura yang terjadi. ${ }^{4}$

Skoliosis struktural biasanya tidak reversibel dan bisa berupa skoliosis idiopatik, kongenital, atau yang didapat (skoliosis neuromuskular). ${ }^{3}$

\section{GEJALA KLINIS}

Gejala-gejala yang paling umum dari skoliosis ialah suatu lekukan yang tidak normal dari tulang belakang. Skoliosis dapat menyebabkan kepala nampak bergeser dari tengah atau satu pinggul atau pundak lebih tinggi daripada sisi berlawanannya. Masalah yang dapat timbul akibat skoliosis ialah penurunan kualitas hidup dan disabilitas, nyeri, deformitas yang mengganggu secara kosmetik, hambatan fungsional, masalah paru, kemungkinan terjadinya progresifitas saat dewasa, dan gangguan psikologis. ${ }^{14,15}$

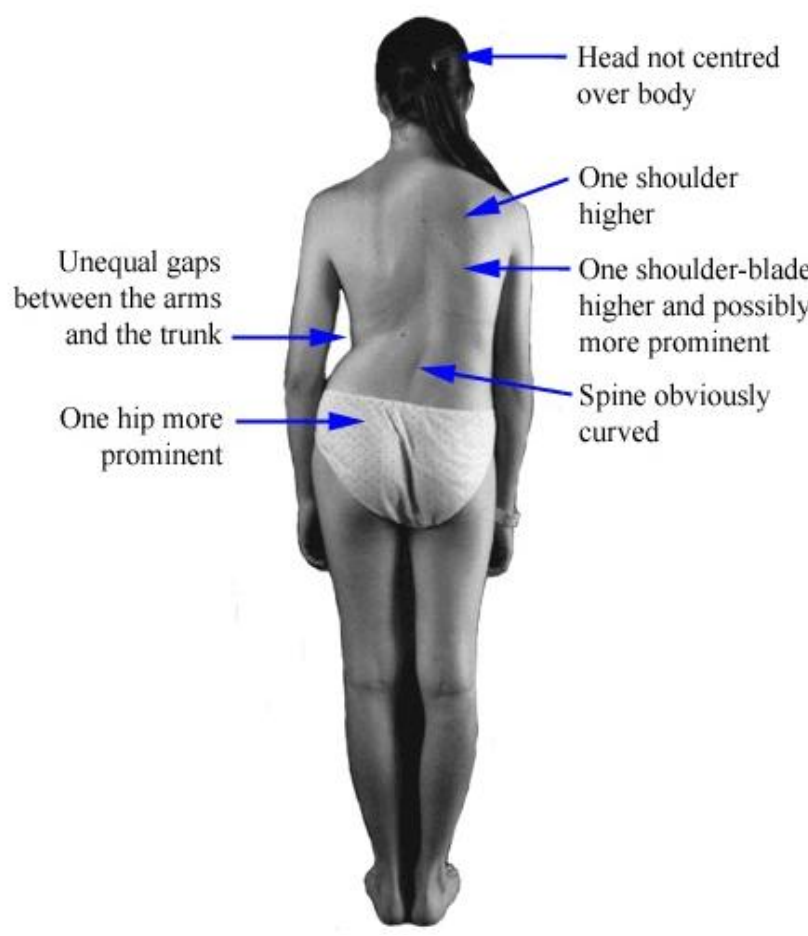

Gambar 2. Gejala klinis skoliosis. Sumber: Scoliosis Australia. ${ }^{16}$

\section{PEMERIKSAAN FISIK}

Pada pemeriksaan skoliosis, baju pasien harus dibuka agar tulang belakang dapat diperiksa secara langsung. Posisi terbaik untuk pemeriksaan ialah posisi berdiri, meskipun pemeriksaan dengan posisi duduk, tidur tengkurap, atau tidur miring juga dapat dilakukan sesuai dengan kondisi pasien. ${ }^{15}$ Hal-hal yang harus diperhatikan pada pemeriksaan fisik ialah deviasi prosesus spinosus dari garis tengah, punggung yang tampak miring, rib hump, asimetri skapula, kesimetrisan pinggul serta bagian atas dan bawah trunkus (bahu dan pelvis), dan perbedaan panjang tungkai. ${ }^{15,17}$

Yang harus dicatat pada saat pemeriksaan skoliosis ialah bentuk dan derajat kurvatura yang terbentuk pada berbagai posisi. Deskripsi kurvatura harus meliputi panjang segmen dimana kurvatura dimulai dan berakhir, bentuk (C atau S), dan arah puncak kurvatura. Skoliometer dapat digunakan untuk mengukur sudut kurvatura tanpa foto radiografi. ${ }^{15}$

\section{PEMERIKSAAN RADIOLOGIK}

Secara tradisional, diagnosis klinis dari skoliosis dan follow up keberhasilan terapi dilakukan dengan menggunakan pemeriksaan radiografi, yang dapat mengukur derajat kurvatura skoliosis secara kuantitatif. Teknik standar untuk mengukur sudut kurvatura skoliosis ialah sudut Cobb. Pemeriksaan radiografi dilakukan dengan posisi berdiri, kecuali jika kondisi pasien tidak memungkinkan maka posisi yang dipilih ialah posisi terlentang. Panggul, pelvis, dan femur, bagian proksimal harus terlihat. Kurva skoliosis dikatakan ringan bila sudut Cobb yang terbentuk $<25^{\circ}$; sedang, bila $25-45^{\circ}$; dan berat, bila $>45^{0} .14$

Pada anak-anak dan remaja, maturitas tulang dilihat dengan garis Risser pada krista iliaka untuk memperkirakan pertumbuhan tulang yang pesat, progresifitas skoliosis, dan berhentinya pertumbuhan. ${ }^{4}$

Kurva skoliosis yang disertai rotasi mungkin lebih sulit untuk ditangani dan mungkin menyebabkan gangguan pada 
rongga dada sehingga dapat mengganggu pernapasan. Secara radiografi, posisi pedikel menunjukkan derajat rotasi yang terbaik. ${ }^{15}$ Pemeriksaan Magnetic Resonance Imaging (MRI) dilakukan atas indikasi nyeri, gangguan neurologik, kurvatura torakal kiri, skoliosis juvenil idiopatik, progresi yang cepat, dan defek kulit. ${ }^{18}$

\section{PENATALAKSANAAN REHABILITA- SI MEDIK PADA SKOLIOSIS}

Indikasi observasi ialah skoliosis dengan sudut kurvatura $<25^{\circ}$ pada pasien yang masih dalam masa pertumbuhan dan $<50^{\circ}$ pada pasien yang masa pertumbuhannya telah berhenti. Pemeriksaan dilakukan setiap 6-9 bulan untuk kurvatura $<20^{\circ}$ dan tiap 4-6 bulan untuk kurvatura $>20^{0} .{ }^{17}$ Peralatan eksternal yang dapat digunakan untuk terapi skoliosis, antara lain gips plaster, brace, atau kombinasi. Tujuan penggunaan alat-alat ini ialah untuk mengoreksi kurvatura skoliosis yang ada atau mempertahankan koreksi yang telah dilakukan oleh terapi operasi. ${ }^{18}$ Penggunaan brace direkomendasikan pada skoliosis dengan kurvatura $>20^{\circ}$ pada pasien yang masih dalam masa pertumbuhan dan dengan progresifitas sebesar 5$10^{0}$ dalam periode 6 bulan. ${ }^{4}$

Milwaukee brace atau Cervico Torakal Lumbo Sacral Orthosis (CTLSO) merupakan brace yang memberikan sanggahan pada pelvis dan koreksi dengan deformitas rotatorik secara statik. ${ }^{19}$ Indikasi penggunaan Milwaukee Brace meliputi skoliosis tahap awal yang sedang berkembang dan mendekati sudut kurvatura $20^{\circ}$. Kurvatura yang melebihi $50^{\circ}$ bukan merupakan kandidat yang tepat untuk penggunaan Milwaukee Brace. ${ }^{19}$ Pemakaian Boston brace paling efektif pada skoliosis dengan puncak kurva di T6 sampai L3. ${ }^{20}$ SpineCor merupakan bentuk ortosis yang fleksibel, dengan tujuan untuk mengurangi hambatan fisik dan meningkatkan tingkat kepatuhan pasien menggunakan ortosis tersebut. ${ }^{21}$

Latihan pada pasien skoliosis bertujuan utama untuk mencegah morbiditas sekunder dan mengurangi proses ekstra- spinal. ${ }^{20}$ Pada kasus skoliosis idiopatik terutama pada pasien yang menggunakan brace, latihan penguatan otot-otot perut dan bokong harus dilakukan untuk mencegah terjadinya atrofi otot. Latihan lingkup gerak sendi fleksor panggul juga harus dilakukan untuk mencegah kontraktur. Latihan yang dilakukan bertujuan untuk memperbaiki postur, meningkatkan fleksibilitas, serta memperbaiki tonus ligamen dan otot. ${ }^{22}$

Latihan dengan metode Klapp meliputi latihan peregangan dan penguatan otot- otot punggung dengan menggunakan posisi kucing dan posisi berlutut yang menyerupai hewan berkaki empat. Latihan ini merupakan bentuk terapi dimana digunakan postur peregangan asimetris. ${ }^{5}$ Berbeda halnya dengan latihan metode Woodcock yang menekankan pola latihan koreksi derotasi dan perbaikan otot intrinsik tulang punggung. Menurut Woodcock, tanpa latihan derotasi, pertambahan kurva sulit dicegah. $^{23}$

Latihan metode $\mathrm{X}$ merupakan kombinasi latihan Woodcock dan Klapp. Latihan ini mudah dikerjakan, dapat dikerjakan setiap hari, dan tidak memerlukan tempat latihan khusus. Frekuensi yang diperlukan untuk bertemu dengan terapis lebih jarang. Latihan ini merupakan modifikasi metode Klapp. Jika pada metode Klapp latihan dilakukan dalam posisi berlutut, maka pada metode $\mathrm{X}$ latihan dilakukan dengan posisi berdiri disertai fleksi trunkus; sudut fleksi trunkus tergantung pada puncak kurvatura. ${ }^{23}$

Metode Schroth ialah salah satu bentuk terapi skoliosis yang menggunakan latihan isometrik dan latihan-latihan lainnya untuk memperkuat dan memperpanjang otot-otot yang asimetris pada skoliosis. Tujuan latihan dengan metode ini ialah untuk memperlambat progresifitas kurvatura spinal yang abnormal, mengurangi nyeri, meningkatkan kapasitas vital, memperbaiki kurvatura yang ada (meskipun tidak 100 $\%$ ), memperbaiki postur dan penampilan, mempertahankan postur yang telah mengalami perbaikan, dan menghindari tindakan operasi. ${ }^{24}$ 


\section{PENANGANAN OPERATIF}

Faktor yang harus dipertimbangkan sebelum operasi ialah fungsi paru pasien dengan penyakit neuromuskuler. Operasi pada kasus skoliosis dilakukan atas indikasi: 1) pasien telah menjalani perawatan dengan brace, namun masih mengalami perburukan kurvatura; 9,19 2) terlambat menggunakan brace, yaitu pada pasien dengan kurva $>50^{\circ}$, usia tulang 15 tahun untuk perempuan dan 17 tahun untuk lakilaki, serta deformitas kurvatura skoliosis yang sangat berat; 3) kurvatura skoliosis $>50^{\circ}$ meskipun tidak dirasakan adanya gangguan kosmetik; ${ }^{19}$ 4) anak yang tidak menggunakan atau tidak dapat menggunakan brace; ${ }^{25} 5$ ) nyeri terus menerus yang mungkin disebabkan oleh skoliosis; 6) skoliosis yang tidak seimbang (unbalanced scoliosis); dan 7) gangguan psikologis karena skoliosis. ${ }^{19}$ Sesuai dengan usia pasien, operasi dapat dilakukan dengan cara instrumentasi tanpa fusi (growing rod) atau operasi fusi definitif yang biasanya dilakukan dengan pendekatan anterior atau posterior. $^{9}$

\section{PROGNOSIS}

Progresivitas skoliosis dapat dipengaruhi oleh jenis kelamin, ukuran kurvatura saat pertama kali ditemukan, tipe dan rotasi kurvatura, serta usia saat onset skoliosis. ${ }^{10,26}$

\section{SIMPULAN}

Skoliosis merupakan kelainan yang sering ditemukan pada anak-anak dan remaja yang menyebabkan disabilitas baik secara fungsional maupun kosmetik. Penatalaksanaan pada kasus skoliosis meliputi observasi, pemberian modalitas, penggunaan orthosis, latihan, dan operasi. Dengan deteksi dini pada pasien yang dicurigai menderita skoliosis dan penatalaksanaan yang tepat, prognosis pasien skoliosis dapat ditingkatkan.

\section{DAFTAR PUSTAKA}

1. Freeman TL, Freeman ED. Musculoskeletal rehabilitation. In: Cucurullo SJ, editor. Physical Medicine and Rehabilitation Board Review. New York: Demos Medical Publishing, 2004; p.281-3.

2. Lau K. Scoliosis: Literature review of current treatment modalities and exercise therapy [serial online]. [cited 2012 Feb 5]. Available from: http://spinal.com.sg/articles/ThesisScolio sisAndExercise.pdf

3. Rossi R, Alexander M. Pediatric Rehabilitation. In: Cucurullo SJ, editor. Physical Medicine and Rehabilitation Board Review. New York: Demos Medical Publishing, 2004; p.665-7.

4. Murphy K, Wunderlich CA, Pico EL, Driscoll SW, Moberg-Wolff E, Rak M, et al. Orthopaedic and musculoskeletal condition. In: Alexander MA, Matthews DJ (editors). Pediatic Rehabilitation Principles and Practice (Fourth Edition). New York: Demos Medical Publishing, 2010; p. 397-405.

5. Iunes DH, Cecilio MBB, Dozza MA, Almeida PR. Quantitative photogrammetric analysis of the Klapp method for treating idiopathic scoliosis. Rev Bras Fisioter. 2010;14(2):133-40.

6. Lyon Brace [homepage on the Internet]. 2008 [cited 2012 Feb 5]. Available from: http://bracingscoliosis.com/ lyon.aspx

7. LaRusso L. Scoliosis [homepage on the Internet]. Nodate [cited $2012 \mathrm{Feb}$ 5]. Available from: http://doctors-hospital. net/util/documents/Scoliosis.pdf

8. Texas Health Resources. Scoliosis [homepage on the Internet]. Nodate [cited 2012 Feb 17]. Available from: http://www.texashealth.org/body.cfm?i $\mathrm{d}=3576$

9. Machida M. Causes of idiopathic scoliosis. Spine 1999;24:2576-83.

10. Kuester V. Idiopathic Scoliosis [homepage on the Internet]. Nodate [cited 2012 Jan 17]. Available from: http://w3.cns. org/university/pediatrics/Scoliosis.html

11. Wong YC, Yau AC, Low WD, Chin NK, Lisowski FP. Ultrastructural changes of the back muscles of idiopathic scoliosis. Spine. 1977;2:251-60. 
12. Nachemson AL, Sahlstrand A. Etiologic factors in adolescent idiopathic scoliosis. Spine. 1977;2:176-84.

13. Reuber M, Schultz A, McNiell T, Spencer D. Trunk muscle myoelectric activities in idiopathic scoliosis. Spine. 1983;8:447-56.

14. Romano M, Minozzi S, Bettany-Saltikov J, Zaina F, Chockalingam N, Kotwicki T, et al. Exercises for adolescent idiopathic scoliosis (Protocol). The Cochrane Library. Issue 4. New Jersey: JohnWiley \& Sons, Ltd.; 2012.

15. Paul SM. Scoliosis and other spinal deformities. In: DeLisa JA, Frontera FW, Gans BM, Walsh NE, Robinson LR, editors. Physical Medicine and Rehabilitation: Principles and Practice (Fourth Edition). Philadelphia: Lippincott Williams \& Wilkins, 2005; p. 679-97.

16. Scoliosis Australia. About scoliosis causes, symptoms, treatment information for patients and parents [homepage on the Internet]. Nodate [cited 2012 Feb 17]. Available from: http://www.scoliosisaustralia.org/scolio sis/about_scoliosis.html

17. Judarwanto W. Gangguan bentuk tulang punggung: Skoliosis [homepage on the Internet]. Nodate [cited 2012 Feb 5]. Avaiable from: www.korananak indonesia.wordpress.com

18. Schwend, RM, Hennrikus W, Hall JE, Emans JB. Childhood scoliosis: Clinical indications for magnetic resonance imaging. J Bone Joint Surg Am. 1995;77(1):46-53.

19. Cailiet R. Scoliosis. Philadelphia: F.A. Davis Company; 1975.

20. Emans JB, Hedequist D, Miller R, Cassella M, Hresko MT, Karin L, et al. Reference Manual for the Boston Scoliosis Brace. Boston Brace International, Inc. 2003

21. Rivard CH, Coillard C. SpineCor System [monograph online]. Nodate [cited 2012 Feb 27]. Available from: http://www.srs.org/professionals/educat ion_materials/SRS_bracing_manual/sec tion13.pdf

22. Negrini S, Antonini G, Carabalona R, Minozzi S. Physical exercises as a treatment for adolescent idiopathic scoliosis. A systematic review. Pediatric Rehabilitation. 2003;6(3-4): 227-35.

23. Thamrinsyam H. Terapi latihan skoliosis pola "X". Simposium Gangguan Tulang Belakang. Manado, 2001.

24. Robinson CM, McMaster MJ: Juvenile IS: Curve pattern and prognosis in 109 patients. J Bone Jt Surg. 1996;78A:1140-48.

25. Moore DP, Tilley E, Sugg P. Spinal orthoses. In: Braddom RL, editor. Physical Medicine \& Rehabilitation (Fourth Edition). Philadelphia: Saunders; 2011; p.359-71.

26. Rinsky LA, Gamble JG. Adolescent idiopathic scoliosis. West J Med. 1988;148:182-91. 